\title{
Assessment of NR4A Ligands that Directly Bind and Modulate the Orphan Nuclear Receptor Nurr1
}

\author{
Paola Munoz-Tello ${ }^{1}$, Hua Lin ${ }^{2,3}$, Pasha Khan ${ }^{2}$, lan Mitchelle S. de Vera ${ }^{1,4}$, Theodore M. Kamenecka ${ }^{2}$, and Douglas J. Kojetin ${ }^{1,2, *}$ \\ ${ }^{1}$ Department of Integrative Structural and Computational Biology, The Scripps Research Institute, Jupiter, FL, 33458, USA \\ 2 Department of Molecular Medicine, The Scripps Research Institute, Jupiter, Florida 33458, USA \\ ${ }^{3}$ Current address: Biomedical Research Center of South China, College of Life Sciences, Fujian Normal University, Fuzhou 350117, China \\ ${ }^{4}$ Current address: Department of Pharmacology and Physiology, Saint Louis University School of Medicine, St. Louis, MO 63104, USA \\ * Correspondence: dkojetin@scripps.edu
}

\begin{abstract}
Nurr1/NR4A2 is an orphan nuclear receptor transcription factor implicated as a potential drug target for neurological disorders including Alzheimer's and Parkinson's diseases. Previous studies identified small molecule modulators of NR4A nuclear receptors including Nurr1 and Nur77/NR4A1; it remains unclear whether these ligands affect Nurr1 through direct binding or indirect non-binding mechanisms. We assessed a panel of twelve ligands reported to affect NR4A activity for Nurr1-dependent and Nurr1-independent transcriptional effects and binding to the Nurr1 ligand-binding domain (LBD). Most of the NR4A ligands show Nurr1-independent effects on transcription in a cell type-specific manner, suggesting they may function through binding to effector proteins whose downstream activities influence Nurr1 function. Protein NMR spectroscopy structural footprinting data show that 4-amino-7-chloroquinoline derivatives (amodiaquine and chloroquine) and cytosporone $B$ directly bind the Nurr1 LBD. In contrast, other NR4A ligands including commercially available compounds such as C-DIM12, celastrol, camptothecin, IP7e, isoalantolactone, and TMPA do not bind the Nurr1 LBD. Interestingly, previous crystal structures indicate that cytosporone $B$ analogs bind to surface pockets in the Nur77 LBD, but protein NMR data indicate cytosporone B likely binds to the Nurr1 orthosteric pocket. These findings should influence medicinal chemistry efforts that desire to optimize Nurr1-binding ligands as opposed to ligands that function through binding to Nurr1 effector proteins.
\end{abstract}

\section{INTRODUCTION}

The NR4A nuclear receptor transcription factors regulate important physiological processes including cellular homeostasis, metabolic regulation, apoptosis, and cell differentiation (1). The three members of the NR4A family-NR4A1 (Nur77), NR4A2 (Nurr1), and NR4A3 (NOR1)regulate the transcription of target genes through binding to specific DNA response element sequences, including a monomeric NGFI-B Response Element (NBRE) motif and a Nur-RXR heterodimer Response Element (NurRE) motif. Nuclear receptors are generally classified as ligand-dependent transcription factors. However, the NR4As have an unconventional orthosteric ligand-binding pocket compared to other nuclear receptors. Crystal structures of the Nur77 and Nurr1 ligand-binding domains (LBDs) show a collapsed orthosteric pocket that is filled with residues containing bulky hydrophobic sidechains suggesting these receptors may function independent of binding ligand within an orthosteric pocket (2, 3). Furthermore, contributing to their status as orphan receptors, it remains unclear if the NR4As are regulated by binding physiological or endogenous ligands, although unsaturated fatty acids (46) and dopamine metabolites (7) have been shown to interaction with the Nur77 and/or Nurr1 LBDs.

Regulating Nurr1 activity with small molecule activating ligands (agonists) is implicated to provide a therapeutic benefit in several Nurr1-related diseases including neurological disorders, inflammation, autoimmunity, cancer, and multiple sclerosis (8-10). To develop therapies to treat these diseases, several groups have initiated studies to discover small molecules that modulate Nurr1 transcription. Among these studies, compounds with a 4-amino-7-chloroquinoline scaffold-including amodiaquine, chloroquine, and glafenine-were identified in a high-throughput screen as ligands that increase Nurr1 transcription in human neuroblastoma SK$N$-BE(2)-C cells (11). Amodiaquine improves behavioral alterations in a Parkinson's disease animal model (11) and improves neuropathology and memory impairment in an Alzheimer's disease animal model (12).

Amodiaquine is the most potent and efficacious Nurr1 agonist of the 4-amino-7-chloroquinoline compounds, but these compounds are not Nurr1 specific; they also target other proteins including apelin receptor (13) and are capable of antiviral $(14,15)$ and antimalarial (16) activity. However, knowledge that the 4-amino-7-chloroquinoline scaffold can directly bind to the Nurr1 LBD opens the path to future structure-activity relationship (SAR) studies to develop more potent and efficacious ligands with better specificity for Nurr1 over other molecular targets. Screening efforts have identified other classes of Nurr1-activating ligands with poorly defined mechanisms of action, and ligands reported to influence Nur77 activity represent another potential source to discover Nurr1 ligands since evolutionarily related nuclear receptors often display broad specificity for similar ligands. This is true for endogenous ligands-e.g., phospholipids for LRH-1 and SF-1, estrogen for ER $\alpha$ and ER $\beta$-as well as synthetic ligands.

It would be useful to know if the Nurr1- and Nur77-activating compounds reported in the literature affect Nurr1 activity through direct binding to Nurr1, or via "off-target" mechanisms through binding to upstream effector proteins whose downstream activities influence Nurr1 function. We tested twelve ligands reported to affect the activity of Nurr1 or Nur77 for Nurr1-dependent transcription using cellular reporter assays and for direct binding to the Nurr1 LBD using a protein NMR structural footprinting assay that provides information on ligand binding epitopes. We found that most of the ligands display cell type-specific transcriptional activities through Nurr1-dependent and Nurr1-independent mechanisms. Furthermore, using protein NMR we found that only three of the ligands directly bind to the Nurr1 LBD: amodiaquine, chloroquine, and cytosporone $\mathrm{B}$. These findings should be of interest to medicinal chemists that want to focus on the discovery and optimization of Nurr1-binding ligands as opposed to ligands that affect Nurr1 activity through other indirect mechanisms.

\section{RESULTS}

\section{NR4A ligand selection and properties}

The twelve ligands we selected represent most, if not all, of the chemical scaffolds reported to modulate Nurr1- or Nur77-dependent transcription or other activities (Figure 1). Of these, nine were available from commercial sources and three others (SR10098, SR24237, and SR10658; compounds $\mathbf{1}, \mathbf{2}$, and $\mathbf{3}$, respectively) were synthesized in-house.

Amodiaquine and chloroquine are antimalarial ligands that contain a 4-amino-7-chloroquinoline scaffold and were identified in a screen using $\mathrm{SK}-\mathrm{N}-\mathrm{BE}(2)-\mathrm{C}$ cells as activators of Nurr1 transcription with micromolar potency that directly bind to the Nurr1 LBD (11).

Four ligands were hits or optimized from a hit identified in different 
high-throughput screens as compounds that increase Nurr1-dependent transcription with low nanomolar potency using a luciferase reporter assay. The benzimidazole SR10098 (17) and the isoxazolo-pyridinone SR10658 (18) were discovered in a screen using the MN9D dopaminergic cellular model; IP7e is an analog of SR10658 reported to have improved solubility for in vivo studies and displayed in vivo efficacy in the experimental autoimmune encephalomyelitis mice (EAE) model of multiple sclerosis (MS) (19). The imidazopyridine SR24237 is an optimized compound from a hit discovered in two screens using Chinese hamster ovary $(\mathrm{CHO})$ and a mouse neuronal N2A cell lines (20). An analog of SR24237 was reported to display neuroprotective and anti-inflammatory activity.

1,1 -bis (3'-indolyl)-1-( $p$-chlorophenyl) methane, or C-DIM12, was reported as a synthetic Nurr1 activator that increases Nurr1 transcription, affects the expression of dopaminergic genes in pancreatic cells, keratinocyte epidermal cells, and primary neurons, and displays in vivo efficacy in models of Parkinson's disease (21-23).

Camptothecin, an antitumor chemotherapeutic agent and cyclooxygenase- 2 inhibi-

tor, is a natural product identified in a high-throughput screen as a potent inhibitor of Nurr1 transcription that triggers an antitumor response by reducing Foxp $3^{+} \mathrm{T}$ regulatory cells and inducing IFN $\gamma^{+} \mathrm{T}$ helper 1 cells indicating Nurr1 may be a target for cancer immunotherapy (24).

Celastrol is a natural product that binds the Nur77 LBD with high affinity and influences Nur77 activity through multiple mechanisms (25). Nur77 and AMPK $\alpha$ are known to be involved in adipogenesis regulation $(26,27)$.

Isoalantolactone is a natural product discovered in a screen for ligands that inhibit Nur77 transcription and activate AMPK $\alpha$ in 3T3-L1 cells leading to a cascade of events that highlights a role for targeting Nur77 in protection against metabolic disorders and obesity (28).

Cytosporone B (CsnB) is a natural product identified as a Nur77 agonist that binds to the Nur7 LBD and enhances interaction of transcriptional coregulator proteins (29). CsnB was also shown to function as a Nurr1 agonist in BGC-823 human gastric carcinoma cells. Later work, using a chemical screen, identified an analog of CsnB called ethyl 2-[2,3,4-trimethoxy-6-(1-octanoyl)phenyl]acetate, or TMPA, that showed low nanomolar affinity for the Nur77 LBD (30). Unlike CsnB, TMPA does not function as a canonical agonist of Nur77 transcription; rather, it inhibits the interaction between Nur77 and Liver kinase B1 (LKB1). Another $\mathrm{CsnB}$ analog that was not commercially available, PDNPA, inhibits the interaction between Nur77 and the MAP kinase p38 $\alpha$ (31), suggesting inhibition of Nur77-kinase interactions may be a general mode of action for these compounds.

\section{Ligands display cell type-specific effects on Nurr1 transcription}

To assess the effect of the compounds on Nurr1-mediated transcription, we transfected cells with a full-length Nurr1 expression plasmid along with one of two reporter plasmids either containing three copies of the NBRE or NurRE followed by the firefly luciferase gene. We performed the assays in three cell lines including HEK293T, a kidney embryonic cell line commonly used to assess general nuclear receptor activity, as well as two cell lines relevant to Nurr1 functions in neurons: PC12, a rat pheochromocytoma cell line exhibiting neuronal-like characteristics; and SK- $N$-BE(2)-C, a neuroblastoma cell line displaying moderate levels of tyrosine hydroxylase activity and dopamine-b-hydroxylase activity. Overall, we found that the ligands showed differential (cell type- or reporter-specific) to negligible activity in the various assays. We used four ligand concentrations in the assays that differ among all the ligands, which we based on previously reported cellular potencies in the original reports of the compounds as well as initial dose-response studies where we excluded higher concentrations that gave bell shaped response curves indicative of colloidal aggregation.

Amodiaquine (Figure 2A) and chloroquine (Figure 2B) increased activity of both luciferase reporters in SK- $N$-BE(2)-C cells consistent with previously published data (11); however, no activity and potentially a slight decrease in luciferase signal was observed for chloroquine in HEK293T and PC12 cells. SR10098 (Figure 2C) increased luciferase activity moderately in HEK293T cells, more efficaciously in SK- $N$-BE(2)-C cells, and showed no effect in PC12 cells. SR24237 (Figure 2D), and SR10658 (Figure 2E) showed dose-responsive increased activity in most conditions. IP7e (Figure $2 \mathrm{~F}$ ) only showed increased activity at the highest concentration tested $(100 \mathrm{nM})$ in all conditions. C-DIM12 (Figure 2G) showed decreased activity in HEK293T and SK-N-BE(2)-C cells, but no effect in PC12 cells. Camptothecin (Figure 2H) showed decreased activity in all conditions except in PC12 cells with the NurRE reporter. Celastrol (Figure 2I) showed increased or decreased activity in a cell type-specific and DNA response element-specific manner. Isoalantolactone (Figure 2J) showed decreased activity in HEK293T and SK- $N$-BE(2)-C cells, but not activity in PC12 cells. Cytosporone B (Figure 2K) showed decreased activity for some conditions at higher concentrations, whereas TMPA (Figure $\mathbf{2 L}$ ) showed no activity. 
bioRxiv preprint doi: https://doi.org/10.1101/2020.05.22.109017; this version posted May 25, 2020. The copyright holder for this preprint (which was not certified by peer review) is the author/funder, who has granted bioRxiv a license to display the preprint in perpetuity. It is made available under aCC-BY 4.0 International license.

$\mathbf{A}$

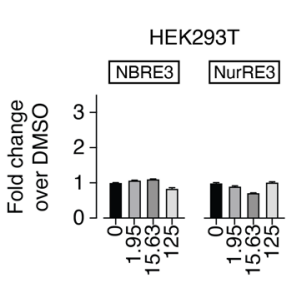

C

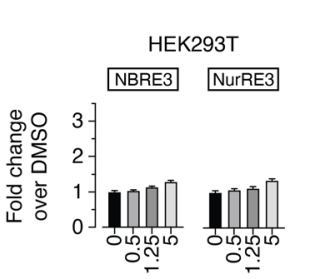

E

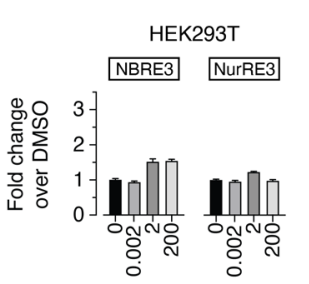

G

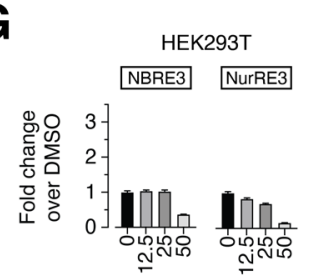

I

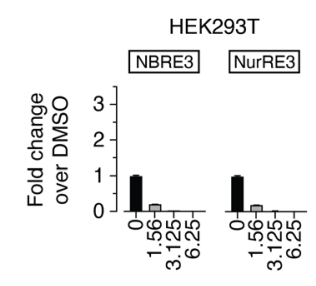

K

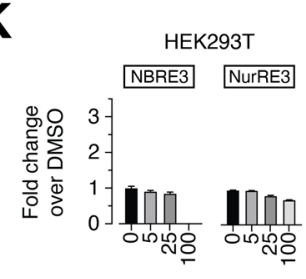

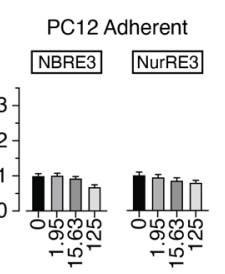

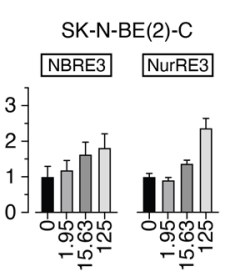

Amodiaquine $(\mu \mathrm{M})$

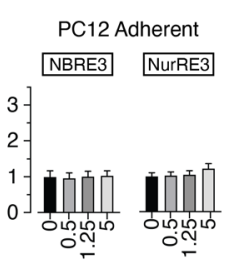

SR10098 ( $\mu \mathrm{M})$

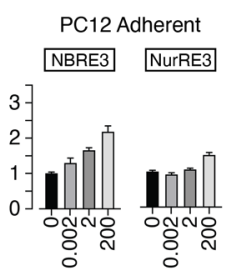

SR10658 (nM)

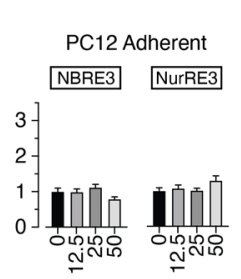

C-DIM12 ( $\mu \mathrm{M})$
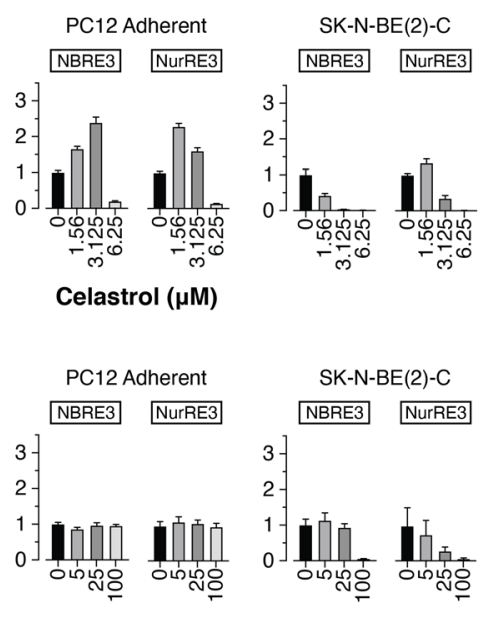

Cytosporone B ( $\mu \mathrm{M})$
B
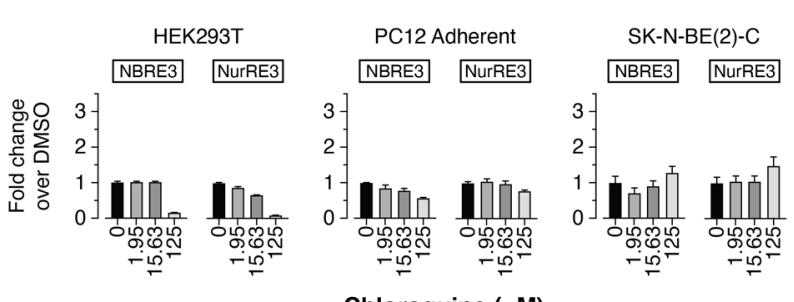

D
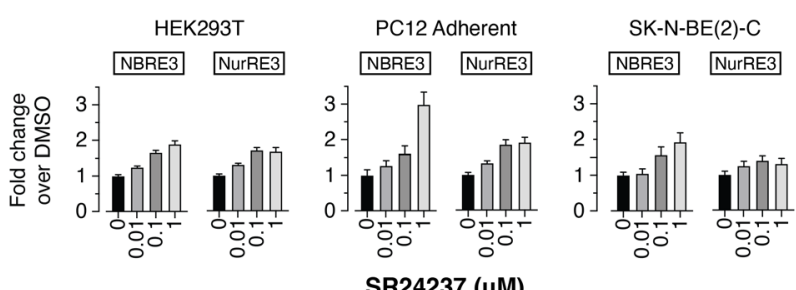

F
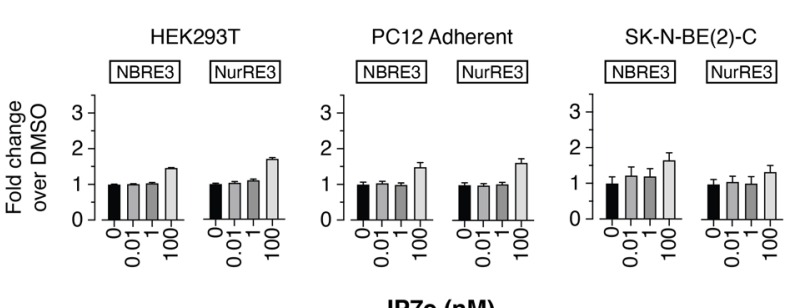

H
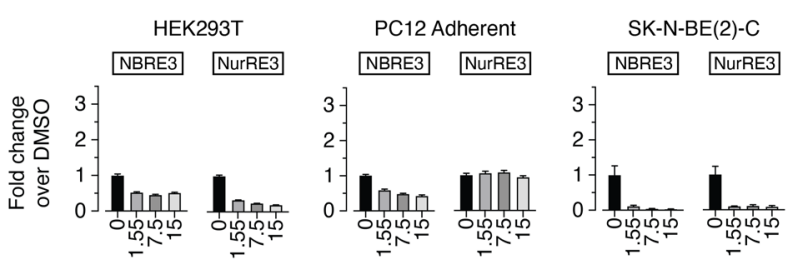

Camptothecin $(\mu \mathrm{M})$

J
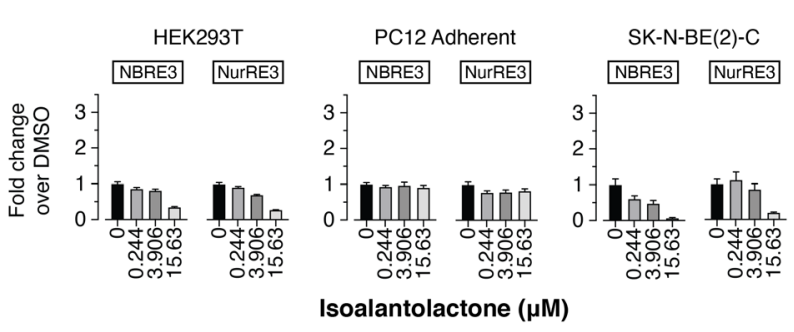

$\mathbf{L}$
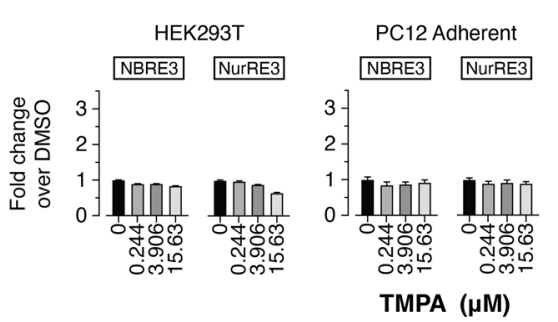

Fig. 2. Effect of the twelve NR4A ligands on full-length Nurr1 transcription of a monomeric NBRE3 and RXR heterodimeric NurRE3 luciferase reporters in HEK293T, PC12, and SK-N-BE(2)-C cells ( $n=4$, mean \pm s.e.m; representative of $\geq 2$ independent experiments).

\section{Ligand transcriptional effects independent of Nurr1}

We performed two cellular assays to determine the specificity of the NR4A compounds in affecting Nurr1 activity at the same ligand concentrations tested in the Nurr1-dependent NBRE and NurRE luciferase assays
(Figure 2) for direct comparison to assess Nurr1-dependent and Nurr1-independent effects on transcription. The first assay tests for compound toxicity and overall effects on general transcription; cells are transfected with a reporter plasmid containing five copies of the yeast Gal4 upstream acti- 
bioRxiv preprint doi: https://doi.org/10.1101/2020.05.22.109017; this version posted May 25, 2020. The copyright holder for this preprint (which was not certified by peer review) is the author/funder, who has granted bioRxiv a license to display the preprint in perpetuity. It is made available under aCC-BY 4.0 International license.

$\mathbf{A}$

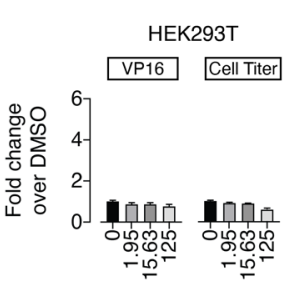

C

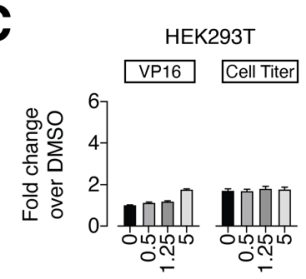

E

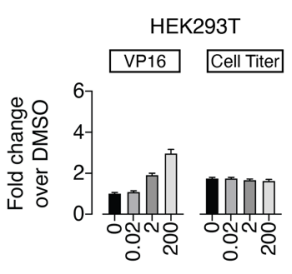

G
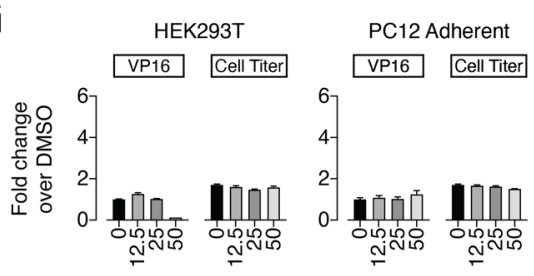

I

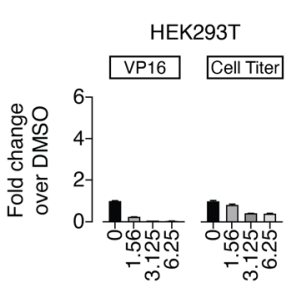

K
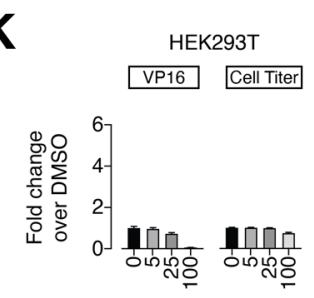
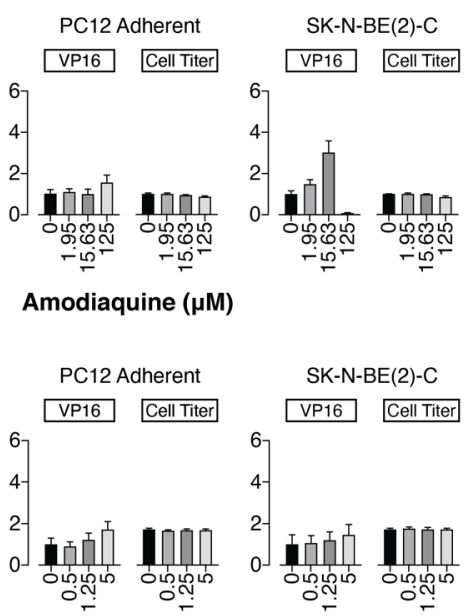

SR10098 ( $\mu \mathrm{M})$

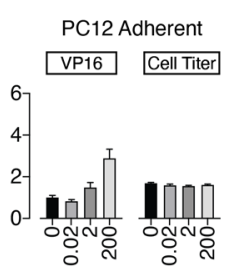

SR10658 (nM)

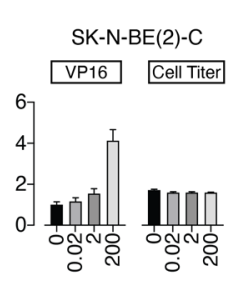

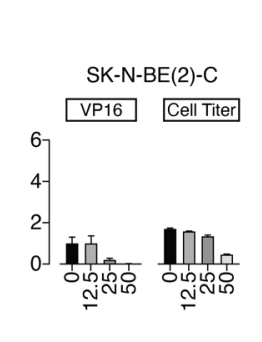
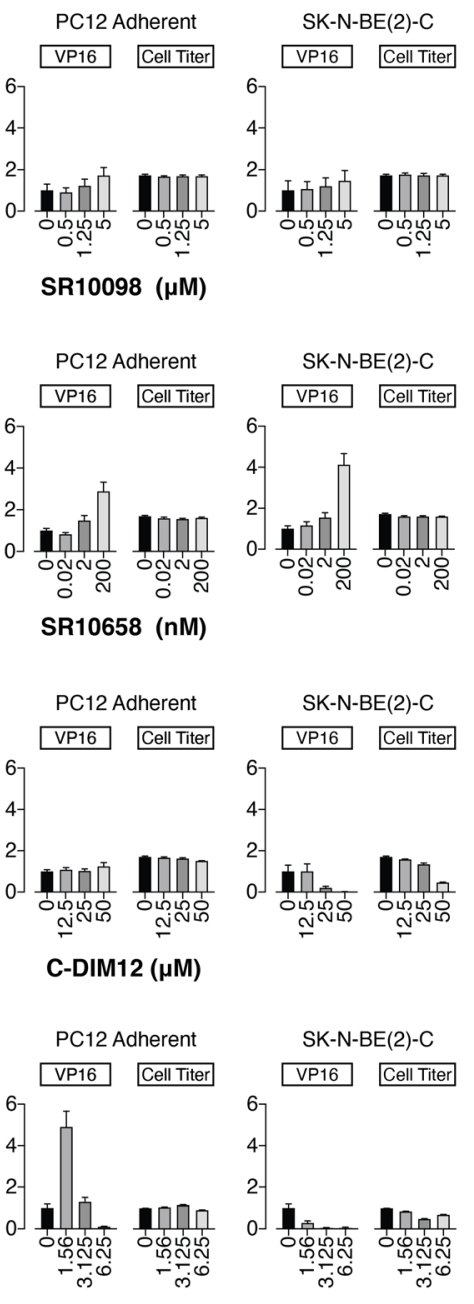

Celastrol ( $\mu \mathrm{M})$

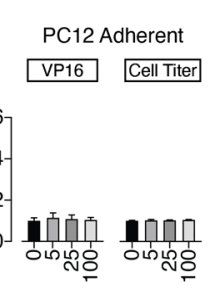

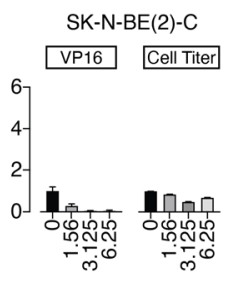
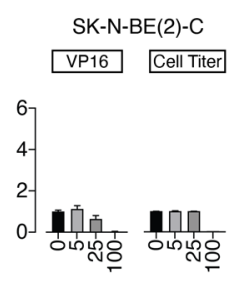

Cytosporone B ( $\mu \mathrm{M})$

B
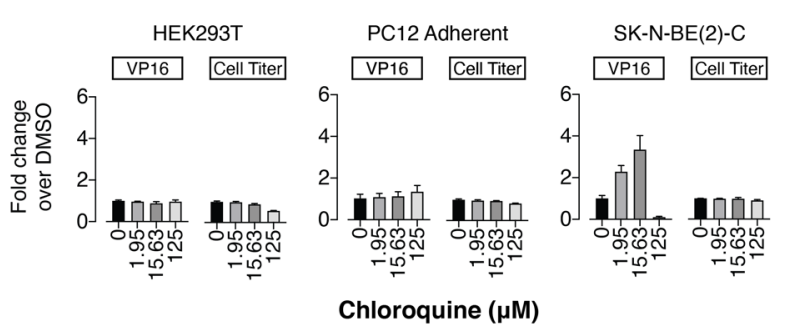

D
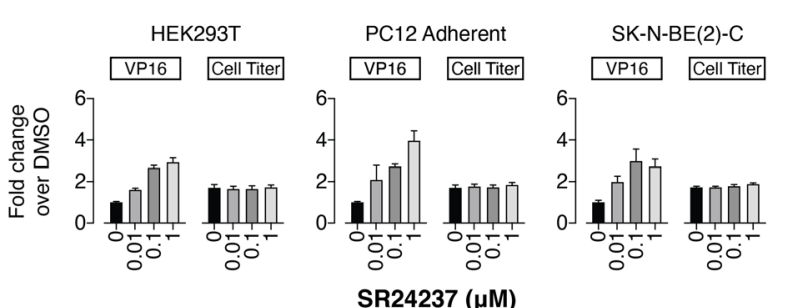

F
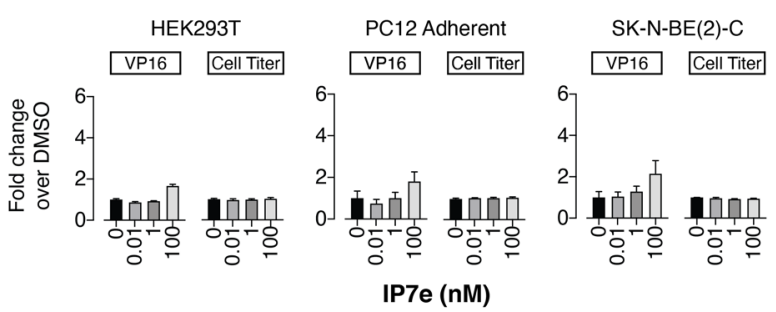

H
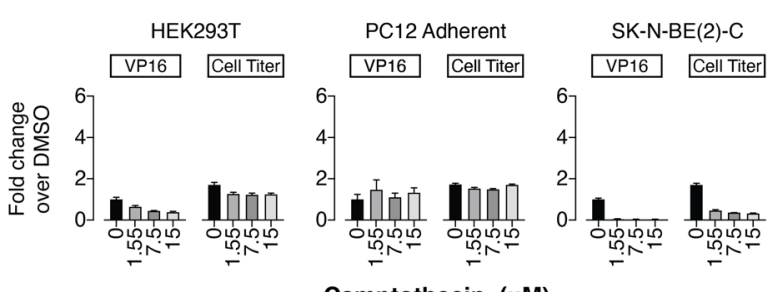

J

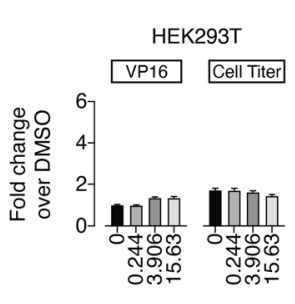

L
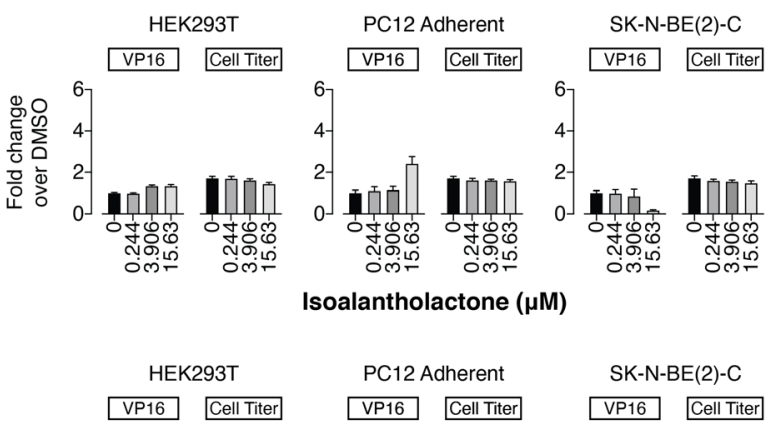

Isoalantholactone $(\mu \mathrm{M})$
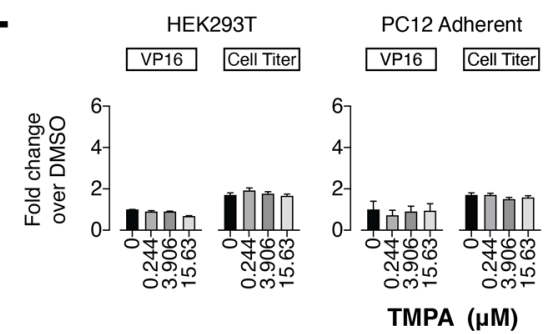

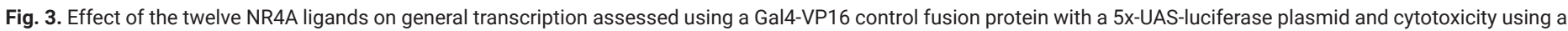
CellTiter-Glo assay in HEK293T, PC12, and SK-N-BE(2)-C cells ( $n=4$, mean \pm s.e.m; representative of $\geq 2$ independent experiments).

vation sequence (UAS) followed by the firefly luciferase gene along with an expression plasmid containing the yeast Gal4 DNA-binding domain fused to the herpes simplex virus protein VP16 activation domain. The Gal4-VP16 fusion protein displays constitutively high luciferase activity; compounds that show decreased activity may either display cytotoxicity or inhibit general transcription in a Nurr1-independent manner, whereas compounds that show increased activity activate general transcription in a Nurr1-indepenent manner. We also tested the compounds using the CellTiter Glo luminescence cell viability assay as a more direct measure of cytotoxicity. 
bioRxiv preprint doi: https://doi.org/10.1101/2020.05.22.109017; this version posted May 25, 2020. The copyright holder for this preprint (which was not certified by peer review) is the author/funder, who has granted bioRxiv a license to display the preprint in perpetuity. It is made available under aCC-BY 4.0 International license.

Amodiaquine (Figure 3A) and chloroquine (Figure 3B) activated VP16 in SK- $N$-BE(2)-C cells at lower concentrations and abruptly decreased activity at the highest concentration tested. However, the compounds only showed cytotoxicity at the highest concentration tested in HEK293T cells, indicating they affect general transcription via Nurr1-independent mechanisms. SR10098 (Figure 3C), SR24237 (Figure 3D), SR10658 (Figure 3E), and IP7e (Figure 3F) activated VP16 in the same cell lines that showed activation in the NBRE and NurRE luciferase assay without any cytotoxicity, indicating they also affect general transcription via Nurr1-independent mechanisms. C-DIM12 (Figure 3G) and camptothecin (Figure $3 \mathrm{H}$ ), which showed decreased Nurr1 activity in some of the NBRE and
NurRE assays, also showed decreased VP16 and/or CellTiter Glo activity in the same cell lines, indicating that Nurr1-independent and cytotoxic mechanisms contribute to activity of these compounds. Finally, celastrol (Figure 3I), isoalantolactone (Figure 3J), cytosporone B (Figure 3K), and TMPA (Figure 3L) showed VP16 and CellTiter Glo activity trends consistent with Nurr1-independent transcriptional mechanisms. Taken together, these data do not rule out that the ligands display Nurr1-dependent transcriptional mechanisms; however, the data indicate most if not all of the ligands also display Nurr1-independent effects on general transcription in a cell type-specific manner in the same conditions where the compounds affected the activity in the NBRE and NurRE assays.

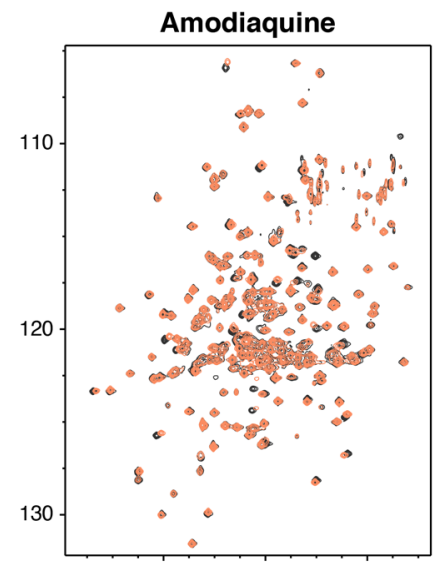

SR10658

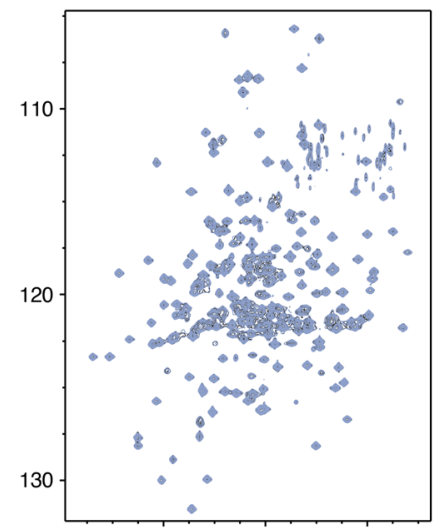

Celastrol

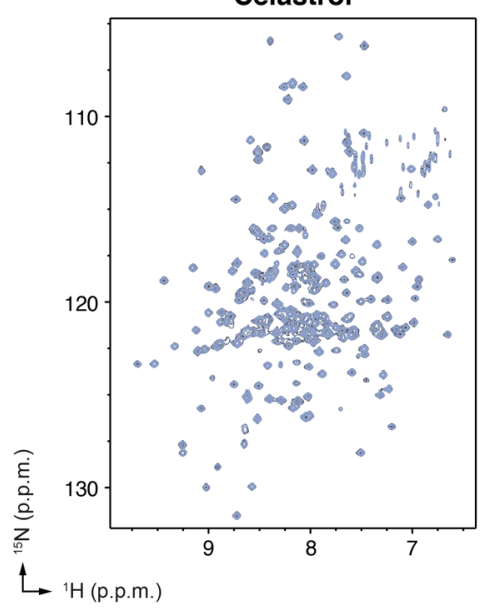

Chloroquine

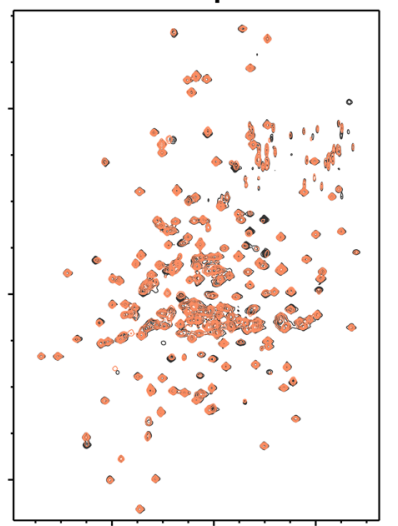

IP7e

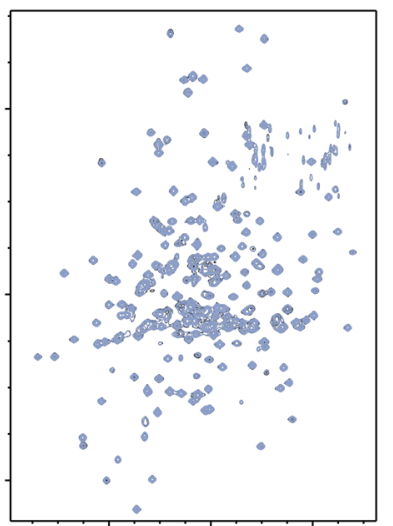

Isoalantolactone

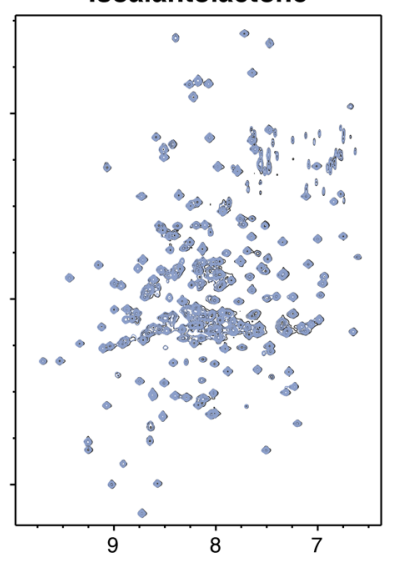

SR10098

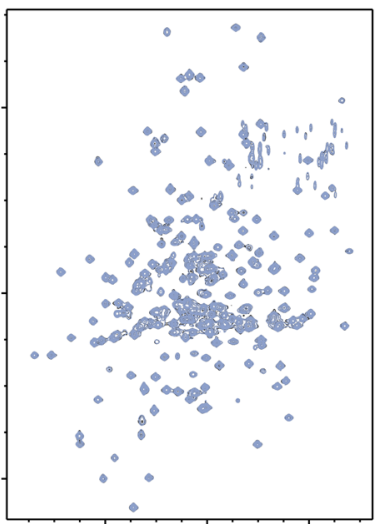

C-DIM12

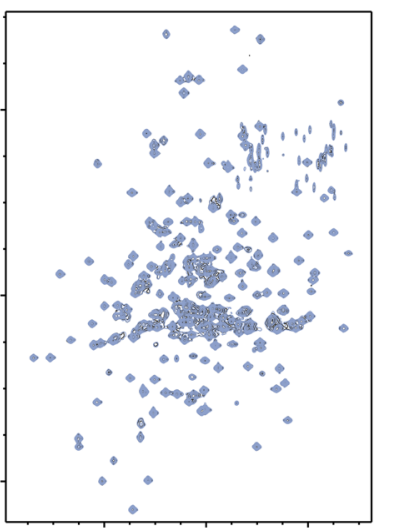

Cytosporone B

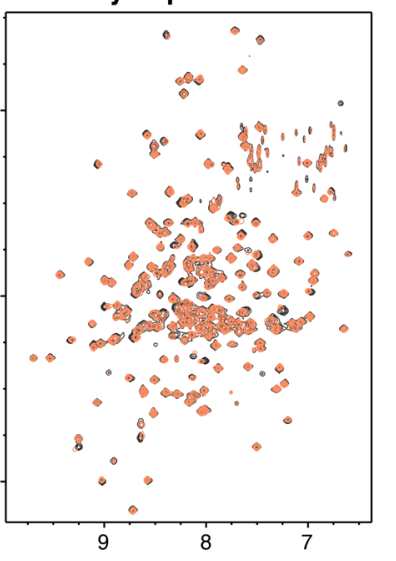

SR24237

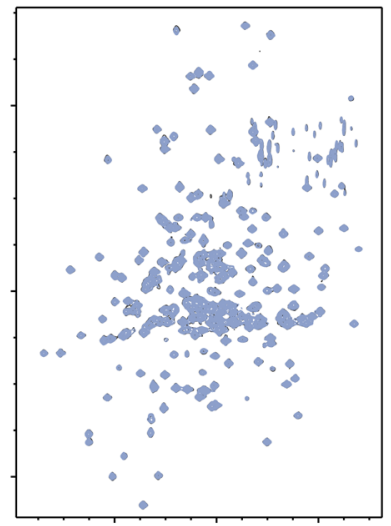

Campothecin

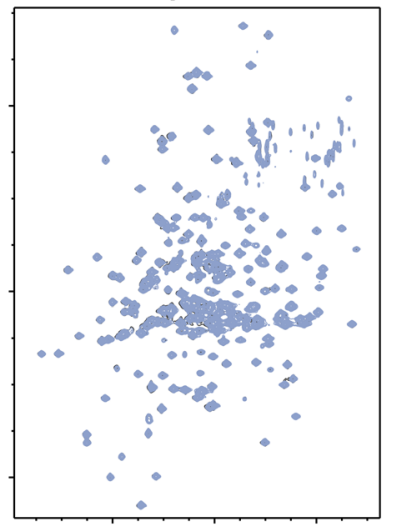

TMPA

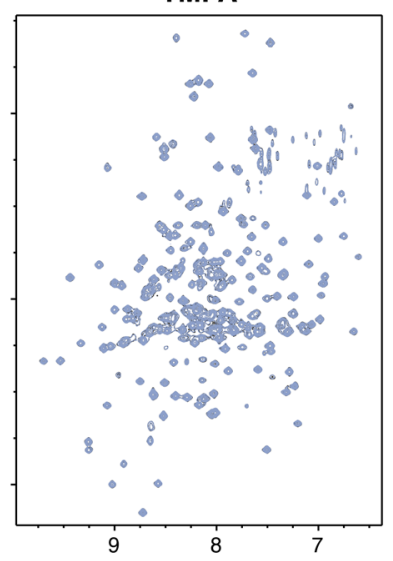

Fig. 4. Protein NMR spectroscopy ligand footprinting data. $2 \mathrm{D}\left[{ }^{1} \mathrm{H},{ }^{15} \mathrm{~N}\right]$-TROSY-HSQC data of ${ }^{15} \mathrm{~N}$-labeled Nurr1 LBD in the absence (black spectra) or presence of $2 \mathrm{X}$ ligand reveals ligands that do not bind to the Nurr1 LBD (blue spectra) and ligands that bind to the Nurr1 LBD (orange spectra). 
bioRxiv preprint doi: https://doi.org/10.1101/2020.05.22.109017; this version posted May 25, 2020. The copyright holder for this preprint (which was not certified by peer review) is the author/funder, who has granted bioRxiv a license to display the preprint in perpetuity. It is made available under aCC-BY 4.0 International license.

A

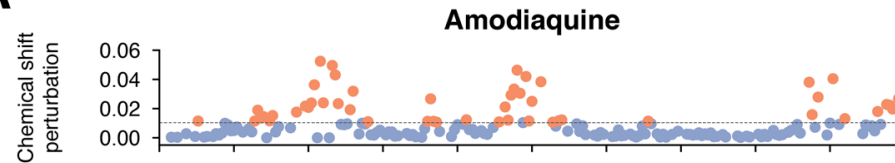

SR10098

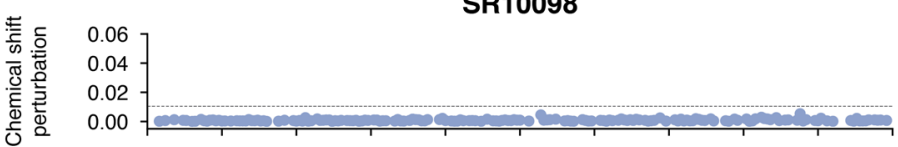

SR10658

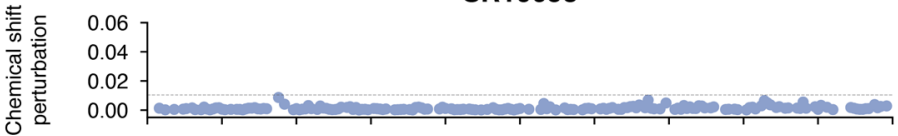

C-DIM12

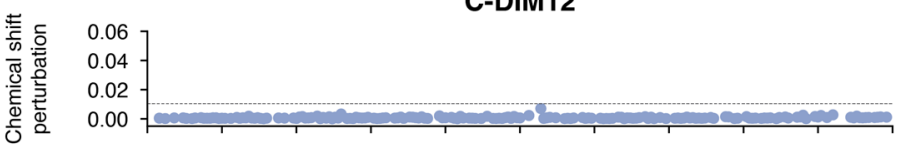

Celastrol

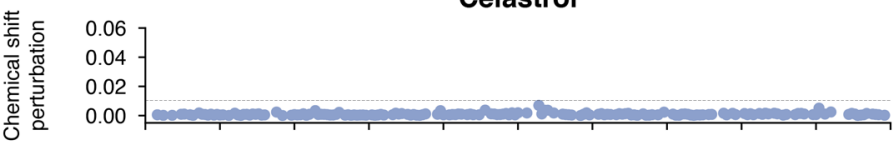

Cytosporone B

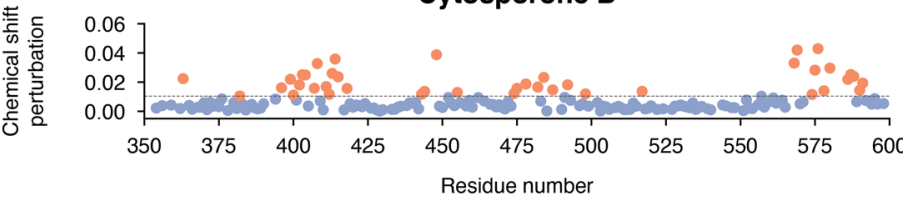

B
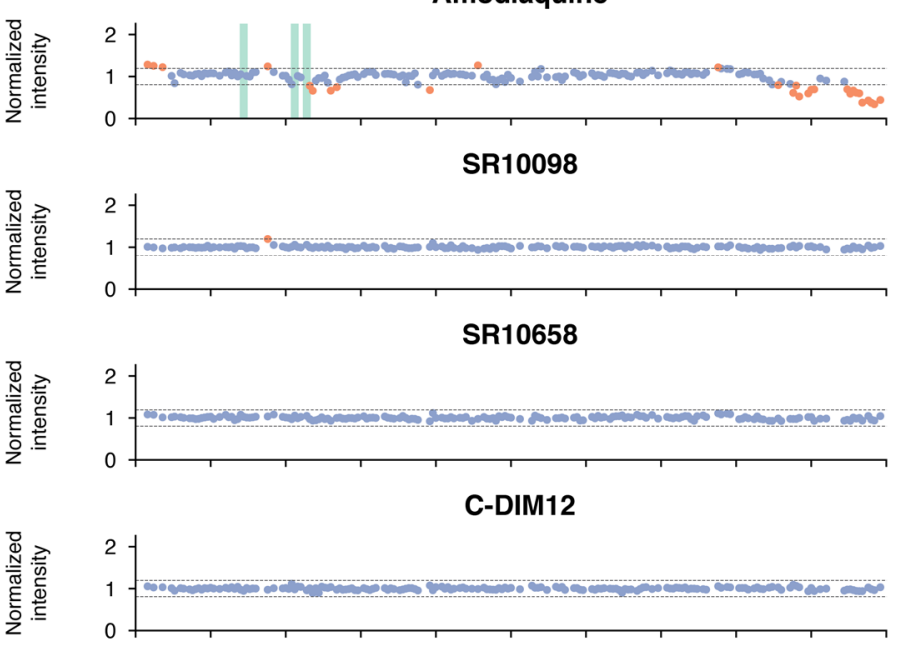

Celastrol

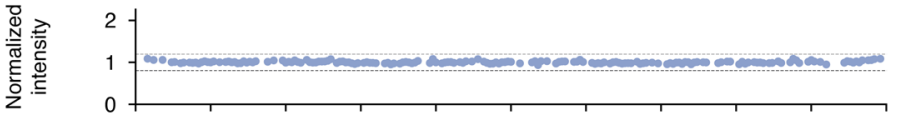

Cytosporone B
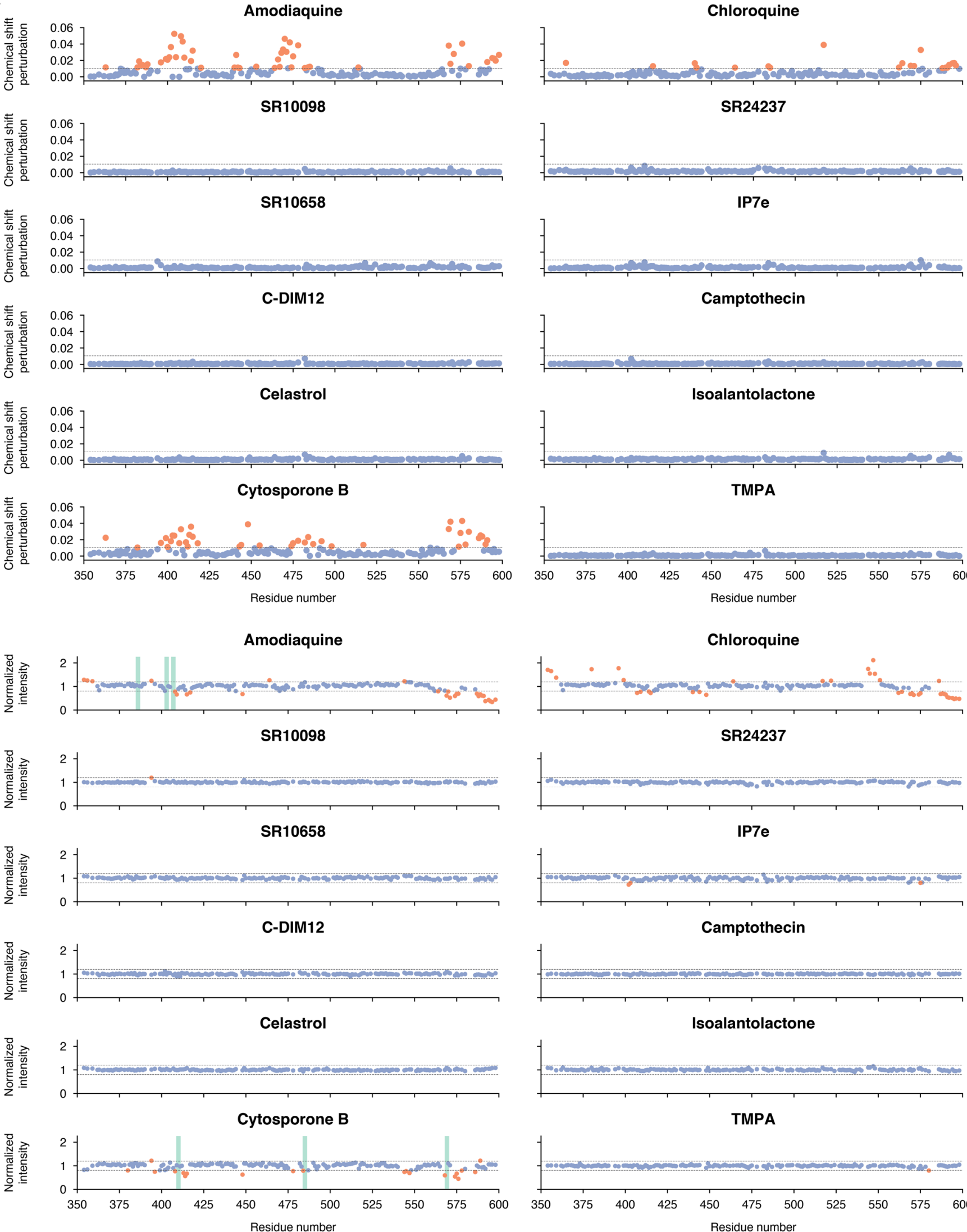

Camptothecin

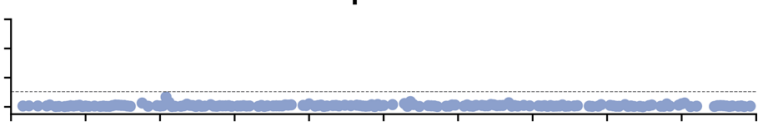

Isoalantolactone

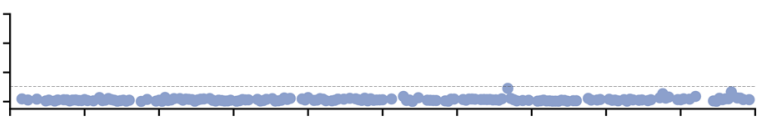

TMPA

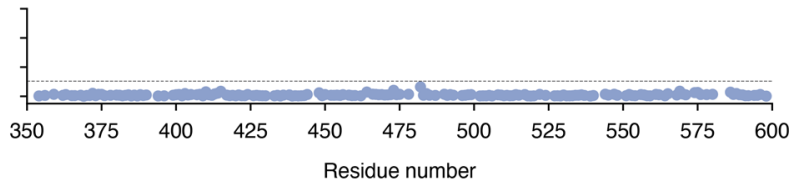

Chloroquine

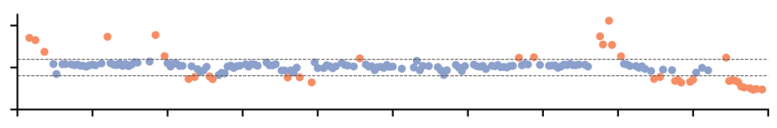

SR24237

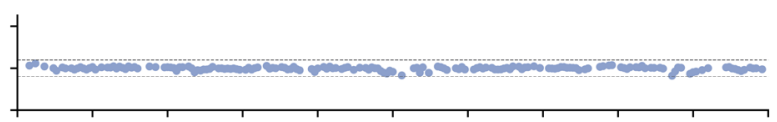

IP7e

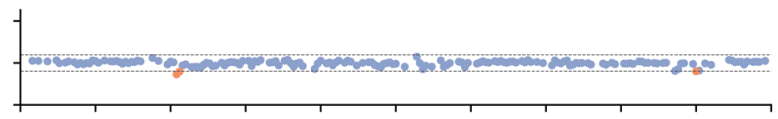

Camptothecin

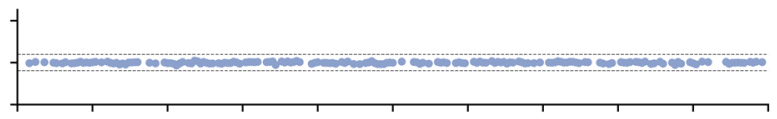

Isoalantolactone

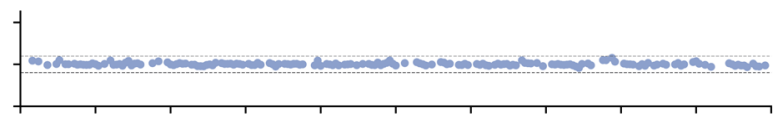

TMPA

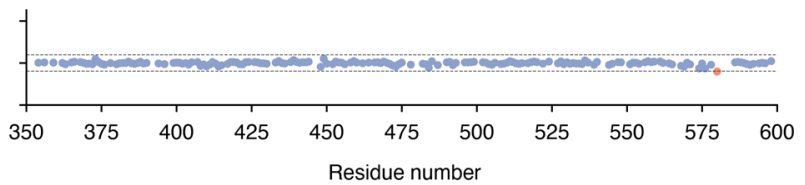

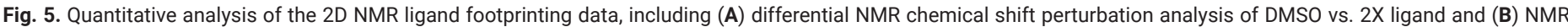

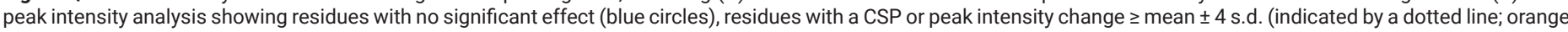
circles), or residues with peak intensities that broadened or decreased into the noise (green bars). 
bioRxiv preprint doi: https://doi.org/10.1101/2020.05.22.109017; this version posted May 25, 2020. The copyright holder for this preprint (which was not certified by peer review) is the author/funder, who has granted bioRxiv a license to display the preprint in perpetuity. It is made available under aCC-BY 4.0 International license.

\section{Protein NMR structural footprinting}

The notion that the NR4A ligands show Nurr1-independent mechanism on general transcription raise a question as to whether they physically interact with and bind to the Nurr1 LBD as opposed to binding upstream effector proteins (e.g., kinases) that in turn regulate Nurr1 transcription through downstream cellular functions. We therefore used a protein NMR spectroscopy structural footprinting assay to determine if the NR4A ligands directly bind to the Nurr1 LBD. We collected $2 \mathrm{D}\left[{ }^{1} \mathrm{H},{ }^{15} \mathrm{~N}\right]-\mathrm{TROSY}-$ HSQC of ${ }^{15} \mathrm{~N}$-labeled Nurr1 LBD in the presence of vehicle control or 2 molar equivalents of ligand (Figure 4). We then calculated the NMR chemical shift perturbation (CSP) (Figure 5A) and NMR line broadening via peak intensity changes (Figure $5 \mathrm{~B}$ ). Consistent with previous data (4, 11), addition of amodiaquine and to a lesser degree chloroquine, which is less potent than amodiaquine (11), showed select NMR CSP and peak intensity changes for Nurr1 LBD residues within helix 3, helix 6, helix 10/11 and helix 12, indicating they directly bind to the Nurr1 LBD. Of the other ten NR4A ligands, only cytosporone B showed NMR structural footprinting results indicating direct binding to the Nurr1 LBD; SR10098, SR24237, SR10658, IP7e, C-DIM12, camptothecin, celastrol, isoalantolactone, and TMPA showed no evidence of binding. The profile of cytosporone B-induced CSP and peak intensity changes are similar to the changes caused by amodiaquine, indicating they share a common binding site within the Nurr1 LBD.

To visualize the NMR-detected binding effects, we mapped the NMR structural footprinting changes for amodiaquine, chloroquine, and cytosporone B, onto the crystal structure of Nurr1 LBD (2) and compared the binding epitopes to the crystal structure of TMPA-bound Nur77 LBD (30), PDNPA-bound Nur77 LBD (31), and the Nur77 modeled binding sites of cytosporone B (29) and celastrol (25) relative to the canonical ligand-binding pocket (Figure 6). Amodiaquine, chloroquine, and cytosporone B show similar binding epitopes on the Nurr1 LBD, which most of the NMR-detected changes occurring for residues within or near the canonical orthosteric-ligand binding pocket. For Nur77, the crystallized TMPA binding poses and modeled celastrol and cytosporone B binding poses are all surface exposed.

Although there is some overlap between the surface exposed Nur77 interaction sites and the Nurr1 NMR-detected binding epitopes, there are also differences. For example, cytosporone B and TMPA are derived from the same scaffold, and the modeled cytosporone B interaction site agrees with one of the two crystallized TMPA binding modes-a solvent exposed surface in the Nur77 LBD. However, the NMR-detected cytosporone B binding epitope on Nurr1 is different, suggesting the interaction occurs within the canonical ligand-binding pocket similar to amodiaquine, chloroquine, and unsaturated fatty acids $(4,5,11)$. These data suggest that cytosporone B likely binds differently to Nurr1 and Nur77, but another explanation could be that the solution NMR structural footprinting analysis picks up on binding events or structural changes that are not apparent in solid state crystallography studies.

\section{DISCUSSION}

Defining if and how ligands bind to Nurr1 is critical not only for understanding Nurr1 function and regulation but also in prioritizing and directing medicinal chemistry efforts on Nurr1-binding ligands. Relative to other nuclear receptors, crystal structures have not revealed a well-defined ligand-binding pocket in the Nurr1 LBD. Solution-state structural studies indicate the Nurr1 ligand-binding pocket is dynamic and solvent accessible, indicating the absence of a pocket captured in Nurr1 LBD crystal structures represents a collapsed conformation (4). The lack of a well-defined Nurr1 ligand binding pocket has arguably stunted efforts to discover and design Nurr1-binding compounds. Several compounds have been reported in the literature to interact with the Nurr1 LBD. Unsaturated fatty acids, amodiaquine, and chloroquine appear to bind to the Nurr1 orthosteric ligand-binding pocket $(4,5,11)$, whereas the endogenous dopamine metabolite 5,6-dihydroxyindole (DHI) covalently binds to noncanonical site via covalent attachment to a surface-exposed cysteine residue in the Nurr1 LBD (7).

Our studies here show that most of the other NR4A ligands that influence the cellular functions of Nurr1 do not appear to function through direct binding to Nurr1. These findings indicate that these ligands exert their effects on Nurr1 activity through binding to upstream effector proteins such as kinases, which could then affect Nurr1 cellular activity via downstream effects. Several other observations support this idea.

First, most if not all of the NR4A ligands show cell type-specific functions. It is possible this is due to the availability of different transcriptional coregulator proteins present within different cell types that could be
NMR-detected ligand binding epitopes mapped onto apo-Nurr1 LBD crystal structure

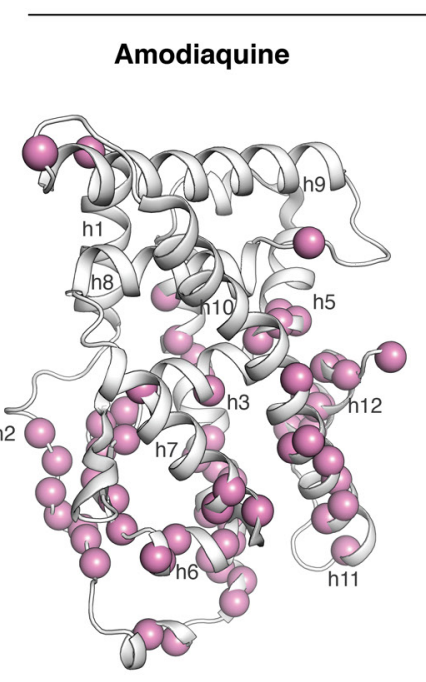

Chloroquine

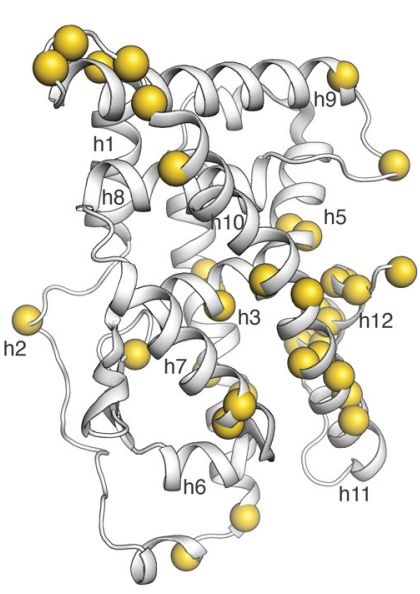

Cytosporone B

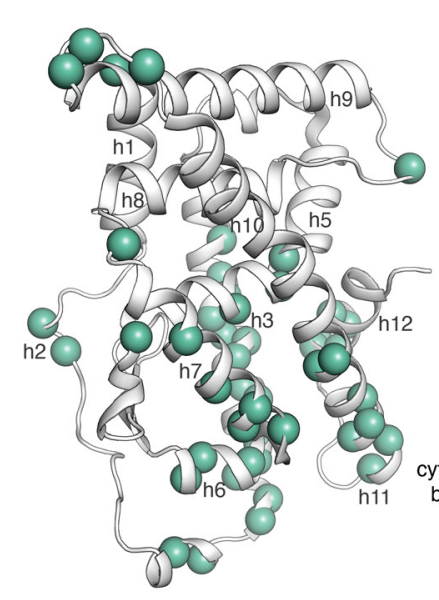

\section{TMPA-bound Nur77 LBD crystal structure}

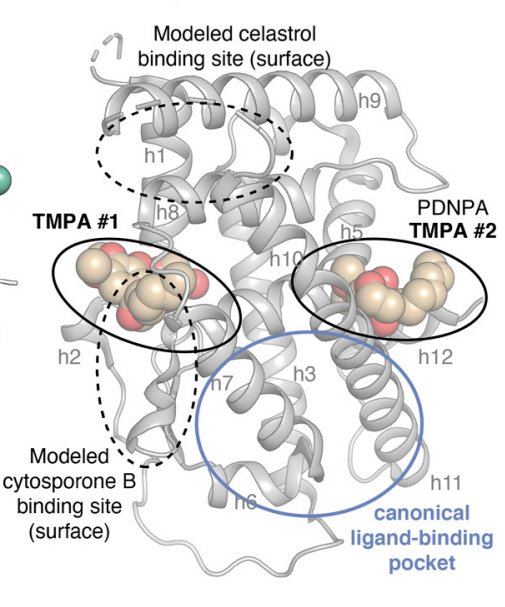

Fig. 6. Mapping the NMR structural footprinting data of the binding ligands onto the Nurr1 LBD crystal structure (PDB 1OVL, chain B) and comparison to TMPA-bound Nur77 LBD (PDB 3V3Q) along with other modeled and crystallized Nur77 ligand binding sites reported in the literature. Spheres indicate residues with NMR CSP or peak intensity values with large changes (mean \pm 4 s.d.) in the $2 \mathrm{D}$ NMR ligand footprinting data. 
recruited to Nurr1 in a ligand-dependent manner. However, given that most of the NR4A ligands do not directly bind Nurr1, it is possible that cell type-specific expression of upstream effector proteins also contributes to the cell type-specific activities of the ligands. Cell type-specific Nurr1 activity has been highlighted previously in neuronal cell lines, suggesting that endogenous factors expressed in specific neuronal cell lines influence Nurr1 activation (32). Cell type-specific dependence may apply to other types including bladder cancer cells and other human cancer cells where Nurr1 activity has been found to be critical for survival (33-35).

Second, some of these NR4A ligands are polypharmacology modulators. As one example, C-DIM12 and related analogs were reported as Nurr1 activators in pancreatic cancer cells (21), bladder cancer cells (34), and neuronal cells $(22,23)$; a Nurr1 inhibitor in glioblastoma cells (36); and activates other nuclear receptors in various cell types including Nur77 (37, 38), COUP-TF1 (39) and PPAR $\gamma$ (40-42). Indeed, previous studies suggest that the mechanisms of action of these C-DIM compounds may occur independent of nuclear receptor binding or via nuclear receptor-independent mechanisms through affectingkinase activity (38, 43-48). In silico ligand docking studies suggested that C-DIM12 may bind to the Nurr1 LBD coregulator binding surface (23). However, our protein NMR structural footprinting data clearly show C-DIM12 does not directly bind to the Nurr1 LBD. Further selectivity profiling such as chemoproteomic methods is warranted to determine the molecular target of C-DIM12 and related analogs.

Related to polypharmacology, some of the other NR4A ligands that we profiled that do not directly bind to the Nurr1 LBD but activate Nurr1 transcription have been shown to function through targets other than the NR4As, which in principle could affect Nurr1 activity through downstream functions of the targets. Celastrol, which contains a reactive quinone methide moiety enabling covalent attachment to cysteine residues (49), including direct binding and inhibition of c-Myc-Max heterodimers (50), cancerous inhibitor of protein phosphatase 2A (CIP2A) (51), STAT3 (52), SHOC-2 to inhibit ERK signaling (53), IKK $\alpha$ and $\operatorname{IKK} \beta$ (54), and HSP90-chaperone interactions (55-57); directly binds nearly 70 protein targets in a proteome microarray assay (53); and affects other cellular signaling pathways including protein phosphatase $2 \mathrm{~A}-\mathrm{Akt}, \mathrm{AMPK}$, and WNT/ $\beta$-catenin (58). Isoalantolactone activates AMPK $\alpha$ (28) and inhibits STAT3 (59) and IKK $\beta$ (60). Camptothecin inhibits topoisomerase I (61). Given that the other Nurr1 activators identified in HTS screens or derived from HTS hits (SR10098, SR10658 and the related analog IP7e, and SR24237) do not directly bind to the Nurr1 LBD, these compounds likely target other effector proteins that influence Nurr1 activity or other general transcriptional machinery since some showed activity in the VP16Gal4 assay. This concept of ligands affecting Nurr1 activity via binding to upstream effectors of Nurr1 is supported by a study showing that kinase inhibitors can activate and inhibit Nurr1 transcription (62). Thus, kinases could act as upstream effector proteins on downstream Nurr1 activities.

Amodiaquine and chloroquine were two of the three compounds in our panel of twelve NR4A ligands that physically bind to the Nurr1 LBD and activated Nurr1 transcription in a screen using SK- $N$-BE(2)-C neuronal cells (11). However, we also found that amodiaquine and chloroquine activated transcription in the VP16-Gal4 assay in SK- $N$-BE(2)-C cells, indicating they also have Nurr1-independent effects on transcription. Amodiaquine is well known as an antimalarial drug mostly used against strains of Plasmodium falciparum (63), but it also inhibits human histamine $\mathrm{N}$-methyltransferase (64) and several human cytochrome P450 enzymes (65). Chloroquine, which is also an antimalarial drug, is a chemokine receptor CXCR4 antagonist (66) and used as anticancer agent capable of inhibiting autophagy by disrupting the fusion of autophagosomes with lysosomes $(67,68)$. Future work on this 4 -aminoquinoline scaffold may result in the development of direct Nurr1-binding compounds with better specificity towards Nurr1 and reduced general effects on transcription.

Our NMR studies show that cytosporone B, which was the first identified Nur77 agonist (29) - but not the related analog TMPA (30)-directly binds to the Nurr1 LBD. We found that cytosporone B did not activate Nurr1 transcription in HEK293T cells or the PC12 and SK- $N$-BE(2)-C neuronal cell lines. However, it is possible that cytosporone B displays cell type-specific activities, as cytosporone B was previously shown to activate Nur77 and Nurr1 in BGC-823 human gastric cancer cells (29). Future studies are needed to detail whether cytosporone B can affect Nurr1 transcription through direct binding in other cell types where Nurr1 is expressed to determine if it represents a potential starting point for future medicinal chemistry efforts on Nurr1-binding ligands.

In conclusion, our studies emphasize the need for determining whether ligands that affect Nurr1 activity, or NR4A activity more broadly, indeed bind directly to Nurr1 or function through upstream effector proteins. Future studies employing biochemical, biophysical, or structure-based screening might lead to new direct binding Nurr1/NR4A ligand scaffolds, which would open new possibilities for developing Nurr1-binding ligands.

\section{MATERIALS AND METHODS}

\section{Compounds and chemical synthesis}

Nine of the twelve NR4A compounds were purchased from commercial vendors: amodiaquine (Xenotech Llc), chloroquine (Chem Impex Intl Inc), IP7e (Tocris), C-DIM12 (Sigma-Aldrich), camptothecin (Cayman), celastrol (Cayman), isoalantolactone (Indofine), cytosporone B (Tocris), and TMPA (EMD Millipore). Three compounds were synthesized in-house using previously described methods including SR10098 (17), SR10658 (18), and SR24237 (20); purity (>95\%) was confirmed using an Agilent 1100 series HPLC system and identity was confirmed by ${ }^{1} \mathrm{H}$ NMR using a Bruker $600 \mathrm{MHz}$ NMR spectrometer and mass analysis using a Thermo Scientific Ultimate 3000/LCQ Fleet system (ESI) mass spectrometer. Compounds were suspended according to vendor recommendations when applicable in water (chloroquine), ethanol- $\mathrm{d}_{6}$ (amodiaquine), or DMSO-d ${ }_{6}$ (all other ligands).

\section{Spectral characterization of synthesized compounds}

1(SR10098). ${ }^{1} \mathrm{H}$ NMR (DMSO-D, $600 \mathrm{MHz}$ ), $\delta$ (p.p.m.): 8.42-8.4 (m, 1H), 8.23-8.19 (m, 2H), 8.16 (dd, $1 \mathrm{H}), 7.79$ (dd, $1 \mathrm{H}), 7.48-7.43$ (m, 2H). MS (ESI): Expected mass for C14H9FN2O2 $(\mathrm{M}+\mathrm{H})^{+}: 256.06 \mathrm{Da}$, observed mass: 256.79 Da.

2 (SR24237). ${ }^{1} \mathrm{H}$ NMR (DMSO-D, $\left.600 \mathrm{MHz}\right), \delta$ (p.p.m.): 10.37 (s, 1H), 9.49 (s, $1 \mathrm{H}), 8.79-8.77(\mathrm{~m}, 1 \mathrm{H}), 8.69(\mathrm{~d}, 1 \mathrm{H}), 8.18(\mathrm{dd}, 1 \mathrm{H}), 8.09(\mathrm{dt}, 1 \mathrm{H})$, 8.03 (dt, 1H), 7.98-7.96 (m, 2H), 7.83 (dt, 1H), 7.49 (ddd, 1H), 7.43-7.39 (m, 1H), 7.18-7.15 (m, 1H). MS (ESI): Expected mass for C19H14N4O (M $+\mathrm{H})^{+}: 314.12 \mathrm{Da}$, observed mass: $314.80 \mathrm{Da}$.

3 (SR10658). ${ }^{1} \mathrm{H}$ NMR (DMSO-D, $600 \mathrm{MHz}$ ), $\delta$ (p.p.m.): 8.17-8.15 (m, $2 \mathrm{H}), 7.53-7.44(\mathrm{~m}, 5 \mathrm{H}), 7.06-7.03(\mathrm{~m}, 2 \mathrm{H}), 6.74$ (s, 1H). MS (ESI): Expected mass for $\mathrm{C} 26 \mathrm{H} 22 \mathrm{~N} 2 \mathrm{O} 3(\mathrm{M}+\mathrm{H})^{+}: 334.13 \mathrm{Da}$, observed mass: $332.87 \mathrm{Da}$.

\section{Cell lines}

All cell lines were obtained from ATCC, including HEK293T (\#CRL11268), PC12 (\#CRL-1721.1), and SK- $N$-BE(2)-C (\#CRL-2268) and cultured according to ATCC guidelines. HEK293 cells were grown at $37^{\circ} \mathrm{C}$, $5 \% \mathrm{CO}_{2}$ in DMEM (Gibco) supplemented with $10 \%$ fetal bovine serum (Gibco) and 100 units $/ \mathrm{mL}$ of Penicillin, $100 \mu \mathrm{g} / \mathrm{mL}$ of Streptomycin and $0.292 \mathrm{mg} / \mathrm{mL}$ of Glutamine (Gibco) until 90 to $95 \%$ confluence prior to subculture or use. SK- $N$-BE(2)-C were maintained at $37^{\circ} \mathrm{C}, 5 \% \mathrm{CO}_{2}$ in a media containing 1:1 mixture of EMEM (ATCC) and F12 medium (Gibco) supplemented with 10\% fetal bovine serum (Gibco) until 90 to $95 \%$ 
confluence prior to subculture or use. PC12 cells were grown at $37{ }^{\circ} \mathrm{C}$, $5 \% \mathrm{CO}_{2}$ in $\mathrm{FK}-12$ medium (Gibco) supplemented with $15 \%$ horse serum (Sigma) and 2.5\% fetal bovine serum (Gibco) until 90 to $95 \%$ confluence prior to subculture or use.

\section{Cellular transcription assays}

HEK293T (\#CRL-11268), PC12 (\#CRL-1721.1), and SK- $N-B E(2)-C$ (\#CRL-2268) cells were seeded in 10-cm petri dish at 1.5 million cells. The following day, cells were transfected using Lipofectamine 2000 (Thermo Fisher Scientific) and Opti-MEM with full-length Nurr1 expression plasmid $(2 \mu \mathrm{g}), 3 \mathrm{xNBRE} 3$ or $3 \mathrm{xNurRE}$-luciferase reporter plasmid (6 $\mu \mathrm{g})$, to a total of $8 \mu \mathrm{g}$ total DNA and incubated for $18 \mathrm{~h}$. For Gal4-VP16 transactivation, cells were transfected the same way but with a Gal4-VP16 expression plasmid $(2 \mu \mathrm{g})$ and $5 x \mathrm{x}$ AS-luciferase reporter plasmid (Upstream Activation Sequence; $2 \mu \mathrm{g}$ ). Cells were transferred to a white 384well plates (Thermo Fisher Scientific) at 10,000 cells/well in $20 \mu \mathrm{L}$ and incubated for $4 \mathrm{~h}$. Ligands were prepared in dose response dilutions using vehicle control: water (chloroquine), ethanol (amodiaquine), or DMSO (all others). Ligand in dose response format or the respective vehicle control were added to the cells $(20 \mu \mathrm{L})$. Cells were then incubated for $18 \mathrm{~h}$ and harvested for luciferase activity quantified using Britelite Plus (Perkin Elmer; $20 \mu \mathrm{L}$ ) on a Synergy Neo plate reader (Biotek). Data were plotted as bars and analysis performed using GraphPad Prism.

\section{Cell viability assays}

HEK293T, PC12 or SK-N-BE(2)-C cells were seeded in 10-cm petri dish at $1.5 \mathrm{M}$ cells. The following day, Cells were transferred to a white 384well plates (Thermo Fisher Scientific) at 10,000 cells/well in $20 \mu \mathrm{L}$ and incubated for $4 \mathrm{~h}$. Ligands (or vehicle control) were added $(20 \mu \mathrm{L})$, cells incubated for $18 \mathrm{~h}$ and harvested for cell viability quantitation using CellTiter-Glo (Promega; $20 \mu \mathrm{L}$ ) on a Synergy Neo plate reader (Biotek).

\section{Expression and purification of ${ }^{15} \mathrm{~N}$-labeled Nurr1 LBD}

Recombinant ${ }^{15} \mathrm{~N}$-labeled Nurr1 LBD (NR4A2; residues 353 to 598) was expressed and purified as previously described (5). Briefly, the protein was expressed in Escherichia coli BL21(DE3) cells (Life Technologies) using a pET-46 tobacco etch virus (TEV) protease-cleavable $\mathrm{N}$-terminal hexahistidine tag fusion protein in M9 media supplemented with ${ }^{15} \mathrm{NH}_{4} \mathrm{Cl}$ (Cambridge Isotope Labs, Inc.). Nurr1 LBD was eluted against a $500 \mathrm{mM}$ imidazole gradient through a Ni-NTA column, followed by overnight dialysis against a buffer without imidazole for TEV protease His tag cleavage at $4{ }^{\circ} \mathrm{C}$. The next morning, the sample is loaded onto the Ni-NTA column for contaminants and tag removal. The flow through containing the purified protein was collected, concentrated and ran through a S75 size exclusion column (GE healthcare) in NMR buffer $\left(20 \mathrm{mM} \mathrm{KPO}_{4} \mathrm{pH}\right.$ 7.4, $50 \mathrm{mM} \mathrm{KCl}$, and $0.5 \mathrm{mM}$ EDTA). The corresponding protein peak is collected and stored at $-80{ }^{\circ} \mathrm{C}$. All the ligands were dissolved in either water, DMSO- $\mathrm{d}_{6}$, or ethanol- $\mathrm{d}_{6}$ for NMR experiments.

\section{Protein NMR spectroscopy structural footprinting}

Data were collected on a Bruker $700 \mathrm{MHz}$ NMR spectrometer equipped with a QCI cryoprobe at $298 \mathrm{~K}$. For each ligand titration, $2 \mathrm{D}\left[{ }^{1} \mathrm{H},{ }^{15} \mathrm{~N}\right]$ TROSY-HSQC were acquired at $298 \mathrm{~K}$ using $200 \mu \mathrm{M}{ }^{15} \mathrm{~N}$-labeled Nurr1 LBD in the absence or presence of $400 \mu \mathrm{M}$ ligand in NMR buffer containing $10 \% \mathrm{D}_{2} \mathrm{O}$. Data were processed using NMRFx (69) and analyzed using NMRViewJ (70). Chemical shift perturbation (CSP) analysis was performed by transfer of Nurr1 LBD NMR chemical shift assignments (71) that we previously validated and reported (5) from the vehicle to the $2 \mathrm{X}$ ligand spectra using the minimal NMR chemical shift method (72). Peaks were identified to have broadened to zero if there was no confident peak in proximity to the vehicle peak. The average CSP and the standard deviation (SD) in the CSPs was calculated for titrations after rejecting outliers more than 2 SD from the mean, and the peaks that displayed CSPs in the presence of peptide greater than $\geq 4$ SD above the average CSP were noted as significant.

\section{REFERENCES}

1. J. A. Herring, W. S. Elison, J. S. Tessem, Function of Nr4a Orphan Nuclear Receptors in Proliferation, Apoptosis and Fuel Utilization Across Tissues. Cells 8, (2019).

2. Z. Wang et al., Structure and function of Nurr1 identifies a class of ligand-independent nuclear receptors. Nature 423, 555-560 (2003).

3. R. Flaig, H. Greschik, C. Peluso-lltis, D. Moras, Structural basis for the cell-specific activities of the NGFI-B and the Nurr1 ligand-binding domain. J Biol Chem 280, 19250-19258 (2005).

4. I. M. S. de Vera et al., Defining a Canonical Ligand-Binding Pocket in the Orphan Nuclear Receptor Nurr1. Structure 27, 66-77 e65 (2019).

5. I. M. de Vera et al., Identification of a Binding Site for Unsaturated Fatty Acids in the Orphan Nuclear Receptor Nurr1. ACS Chem Biol 11, 1795-1799 (2016).

6. N. Vinayavekhin, A. Saghatelian, Discovery of a protein-metabolite interaction between unsaturated fatty acids and the nuclear receptor Nur77 using a metabolomics approach. $J$ Am Chem Soc 133, 17168-17171 (2011).

7. J. M. Bruning et al., Covalent Modification and Regulation of the Nuclear Receptor Nurr1 by a Dopamine Metabolite. Cell Chem Biol 26, 674-685 e676 (2019).

8. S. Safe et al., Nuclear receptor 4A (NR4A) family - orphans no more. J Steroid Biochem Mol Biol 157, 48-60 (2016).

9. T. Sekiya et al., The nuclear orphan receptor $\mathrm{Nr} 4 \mathrm{a} 2$ induces Foxp3 and regulates differentiation of CD4+ T cells. Nat Commun 2, 269 (2011).

10. T. Sekiya et al., Nr4a receptors are essential for thymic regulatory $\mathrm{T}$ cell development and immune homeostasis. Nat Immunol 14, 230-237 (2013).

11. C. H. Kim et al., Nuclear receptor Nurr1 agonists enhance its dual functions and improve behavioral deficits in an animal model of Parkinson's disease. Proc Natl Acad Sci U S A 112, 8756-8761 (2015).

12. M. Moon et al., Nurr1 (NR4A2) regulates Alzheimer's disease-related pathogenesis and cognitive function in the 5XFAD mouse model. Aging Cell 18, e12866 (2019).

13. D. McAnally et al., Repurposing antimalarial aminoquinolines and related compounds for treatment of retinal neovascularization. PLoS One 13, e0202436 (2018).

14. Y. Han, H. T. Pham, H. Xu, Y. Quan, T. Mesplede, Antimalarial drugs and their metabolites are potent Zika virus inhibitors. J Med Virol 91, 1182-1190 (2019).

15. Y. Sakurai, N. Sakakibara, M. Toyama, M. Baba, R. A. Davey, Novel amodiaquine derivatives potently inhibit Ebola virus infection. Antiviral Res 160, 175-182 (2018).

16. D. J. Sullivan, Jr., I. Y. Gluzman, D. G. Russell, D. E. Goldberg, On the molecular mechanism of chloroquine's antimalarial action. Proc Natl Acad Sci U S A 93, 11865-11870 (1996).

17. C. Dubois, B. Hengerer, H. Mattes, Identification of a potent agonist of the orphan nuclear receptor Nurr1. ChemMedChem 1, 955-958 (2006).

18. S. Hintermann et al., Identification of a series of highly potent activators of the Nurr1 signaling pathway. Bioorg Med Chem Lett 17, 193-196 (2007).

19. F. Montarolo et al., Effects of isoxazolo-pyridinone 7e, a potent activator of the Nurr1 signaling pathway, on experimental autoimmune encephalomyelitis in mice. PLoS One $\mathbf{9}$ e108791 (2014).

20. D. Lesuisse et al., Development of a novel NURR1/NOT agonist from hit to lead and candidate for the potential treatment of Parkinson's disease. Bioorg Med Chem Lett 29, 929-932 (2019).

21. X. Li, S. O. Lee, S. Safe, Structure-dependent activation of NR4A2 (Nurr1) by 1,1-bis(3'-indolyl)-1-(aromatic)methane analogs in pancreatic cancer cells. Biochem Pharmacol 83 1445-1455 (2012).

22. S. L. Hammond, S. Safe, R. B. Tjalkens, A novel synthetic activator of Nurr1 induces dopaminergic gene expression and protects against 6-hydroxydopamine neurotoxicity in vitro. Neurosci Lett 607, 83-89 (2015).

23. S. L. Hammond et al., The Nurr1 Ligand,1,1-bis(3'-Indolyl)-1-(p-Chlorophenyl)Methane, Modulates Glial Reactivity and Is Neuroprotective in MPTP-Induced Parkinsonism. J Pharmacol Exp Ther 365, 636-651 (2018).

24. S. Hibino et al., Inhibition of Nr4a Receptors Enhances Antitumor Immunity by Breaking Treg-Mediated Immune Tolerance. Cancer Res 78, 3027-3040 (2018).

25. M. Hu et al., Celastrol-Induced Nur77 Interaction with TRAF2 Alleviates Inflammation by Promoting Mitochondrial Ubiquitination and Autophagy. Mol Cell 66, 141-153 e146 (2017).

26. S. Bijland, S. J. Mancini, I. P. Salt, Role of AMP-activated protein kinase in adipose tissue metabolism and inflammation. Clin Sci (Lond) 124, 491-507 (2013).

27. M. Fu et al., A Nuclear Receptor Atlas: 3T3-L1 adipogenesis. Mol Endocrinol 19, $2437-$ 2450 (2005).

28. Y. S. Jung et al., Dual targeting of Nur77 and AMPKalpha by isoalantolactone inhibits adipogenesis in vitro and decreases body fat mass in vivo. Int J Obes (Lond) 43, 952-962 (2019).

29. Y. Zhan et al., Cytosporone B is an agonist for nuclear orphan receptor Nur77. Nat Chem Biol 4, 548-556 (2008).

30. Y. Y. Zhan et al., The orphan nuclear receptor Nur77 regulates LKB1 localization and 
bioRxiv preprint doi: https://doi.org/10.1101/2020.05.22.109017; this version posted May 25, 2020. The copyright holder for this preprint (which was not certified by peer review) is the author/funder, who has granted bioRxiv a license to display the preprint in perpetuity. It is made available under aCC-BY 4.0 International license.

activates AMPK. Nat Chem Biol 8, 897-904 (2012)

31. L. Li et al., Impeding the interaction between Nur77 and p38 reduces LPS-induced inflammation. Nat Chem Biol 11, 339-346 (2015).

32. D. S. Castro, M. Arvidsson, M. Bondesson Bolin, T. Perlmann, Activity of the Nurr1 carboxyl-terminal domain depends on cell type and integrity of the activation function 2. J Biol Chem 274, 37483-37490 (1999).

33. J. Guo, G. Zu, T. Zhou, J. Xing, Z. Wang, Clinicopathological significance of orphan nuclear receptor Nurr1 expression in gastric cancer. Clin Transl Oncol 17, 788-794 (2015).

34. T. Inamoto et al., 1,1-Bis(3'-indolyl)-1-(p-chlorophenyl)methane activates the orphan nuclear receptor Nurr1 and inhibits bladder cancer growth. Mol Cancer Ther 7, 3825-3833 (2008).

35. J. Wang, J. Yang, B. B. Li, Z. W. He, High cytoplasmic expression of the orphan nuclear receptor NR4A2 predicts poor survival in nasopharyngeal carcinoma. Asian Pac J Cancer Prev 14, 2805-2809 (2013).

36. K. Karki et al., Nuclear receptor 4A2 (NR4A2) is a druggable target for glioblastomas. $J$ Neurooncol 146, 25-39 (2020).

37. S. Chintharlapalli et al., Activation of Nur77 by selected 1,1-Bis(3'-indolyl)-1-(p-substituted phenyl)methanes induces apoptosis through nuclear pathways. J Biol Chem 280, 24903-24914 (2005)

38. S. D. Cho et al., Nur77 agonists induce proapoptotic genes and responses in colon cancer cells through nuclear receptor-dependent and nuclear receptor-independent pathways. Cancer Res 67, 674-683 (2007).

39. K. Yoon et al., Activation of COUP-TFI by a Novel Diindolylmethane Derivative. Cells 8 , (2019).

40. S. Chintharlapalli, R. Smith, 3rd, I. Samudio, W. Zhang, S. Safe, 1,1-Bis(3'-indo$|y|)-1$-(p-substitutedphenyl)methanes induce peroxisome proliferator-activated receptor gamma-mediated growth inhibition, transactivation, and differentiation markers in colon cancer cells. Cancer Res 64, 5994-6001 (2004).

41. C. Qin et al., A new class of peroxisome proliferator-activated receptor gamma (PPARgamma) agonists that inhibit growth of breast cancer cells: 1,1-Bis(3'-indolyl)-1-(p-substituted phenyl)methanes. Mol Cancer Ther 3, 247-260 (2004).

42. R. B. Tjalkens et al., The peroxisome proliferator-activated receptor-gamma agonist 1,1-bis(3'-indolyl)-1-(p-trifluoromethylphenyl)methane suppresses manganese-induced production of nitric oxide in astrocytes and inhibits apoptosis in cocultured PC12 cells. $J$ Neurosci Res 86, 618-629 (2008).

43. P. Lei, M. Abdelrahim, S. D. Cho, X. Liu, S. Safe, Structure-dependent activation of endoplasmic reticulum stress-mediated apoptosis in pancreatic cancer by $1,1-$-bis (3'-indoly)-1-(p-substituted phenyl)methanes. Mol Cancer Ther 7, 3363-3372 (2008).

44. P. Lei et al., 1,1-Bis(3'-indolyl)-1-(p-substituted phenyl)methanes inhibit colon cancer cell and tumor growth through activation of $\mathrm{c}$-jun $\mathrm{N}$-terminal kinase. Carcinogenesis 29, 1139-1147 (2008).

45. A. A. Goldberg et al., 3,3'-Diindolylmethane (DIM) and its ring-substituted halogenated analogs (ring-DIMs) induce differential mechanisms of survival and death in androgen-dependent and -independent prostate cancer cells. Genes Cancer 6, 265-280 (2015).

46. S. D. Cho et al., 1,1-bis(3'-indolyl)-1-(p-methoxyphenyl)methane activates Nur77-independent proapoptotic responses in colon cancer cells. Mol Carcinog 47, 252-263 (2008).

47. S. Chintharlapalli, S. Papineni, S. Safe, 1,1-bis(3'-indolyl)-1-(p-substitutedphenyl)methanes inhibit growth, induce apoptosis, and decrease the androgen receptor in LNCaP prostate cancer cells through peroxisome proliferator-activated receptor gamma-independent pathways. Mol Pharmacol 71, 558-569 (2007)

48. P. Lei, M. Abdelrahim, S. Safe, 1,1-Bis(3'-indolyl)-1-(p-substituted phenyl)methanes inhibit ovarian cancer cell growth through peroxisome proliferator-activated receptor-dependent and independent pathways. Mol Cancer Ther 5, 2324-2336 (2006).

49. A. Salminen, M. Lehtonen, T. Paimela, K. Kaarniranta, Celastrol: Molecular targets of Thunder God Vine. Biochem Biophys Res Commun 394, 439-442 (2010).

50. H. Wang et al., Direct inhibition of c-Myc-Max heterodimers by celastrol and celastrol-inspired triterpenoids. Oncotarget 6, 32380-32395 (2015)

51. Z. Liu et al., Cancerous inhibitor of PP2A is targeted by natural compound celastrol for degradation in non-small-cell lung cancer. Carcinogenesis 35, 905-914 (2014).

52. S. Ye et al., Celastrol Attenuates Angiotensin II-Induced Cardiac Remodeling by Targeting STAT3. Circ Res 126, 1007-1023 (2020).

53. H. Xiao-Pei et al., Systematic identification of Celastrol-binding proteins reveals that Shoc2 is inhibited by Celastrol. Biosci Rep 38, (2018).

54. J. H. Lee et al., Inhibition of NF-kappa B activation through targeting I kappa B kinase by celastrol, a quinone methide triterpenoid. Biochem Pharmacol 72, 1311-1321 (2006).

55. A. Chadli et al., Celastrol inhibits Hsp90 chaperoning of steroid receptors by inducing fibrillization of the Co-chaperone p23. J Biol Chem 285, 4224-4231 (2010).

56. T. Zhang et al., A novel Hsp90 inhibitor to disrupt Hsp90/Cdc37 complex against pancreatic cancer cells. Mol Cancer Ther 7, 162-170 (2008).

57. T. Zhang et al., Characterization of celastrol to inhibit hsp90 and cdc37 interaction. $J$ Biol Chem 284, 35381-35389 (2009).

58. S. R. Chen et al., A Mechanistic Overview of Triptolide and Celastrol, Natural Products from Tripterygium wilfordii Hook F. Front Pharmacol 9, 104 (2018).

59. W. Chen et al., Isoalantolactone induces apoptosis through ROS-mediated ER stress and inhibition of STAT3 in prostate cancer cells. J Exp Clin Cancer Res 37, 309 (2018).

60. J. S. Xing et al., Isoalantolactone inhibits IKKbeta kinase activity to interrupt the
NF-kappaB/COX-2-mediated signaling cascade and induces apoptosis regulated by the mitochondrial translocation of cofilin in glioblastoma. Cancer Med 8, 1655-1670 (2019).

61. F. Li, T. Jiang, Q. Li, X. Ling, Camptothecin (CPT) and its derivatives are known to target topoisomerase I (Top1) as their mechanism of action: did we miss something in CPT analogue molecular targets for treating human disease such as cancer? Am J Cancer Res 7, 2350-2394 (2017).

62. K. L. Williams, C. I. Wells, J. T. Moore, Identification of Kinase Inhibitors that Regulate Nuclear Receptor Nurr1 (NR4A2) Cellular Activity. bioRxiv, 420976 (2019).

63. S. T. Mariga, J. P. Gil, C. Sisowath, W. H. Wernsdorfer, A. Bjorkman, Synergism between amodiaquine and its major metabolite, desethylamodiaquine, against Plasmodium falciparum in vitro. Antimicrob Agents Chemother 48, 4089-4096 (2004).

64. A. Yokoyama et al., Effect of amodiaquine, a histamine $\mathrm{N}$-methyltransferase inhibitor, on, Propionibacterium acnes and lipopolysaccharide-induced hepatitis in mice. Eur J Pharmacol 558, 179-184 (2007).

65. A. Wennerholm et al., Amodiaquine, its desethylated metabolite, or both, inhibit the metabolism of debrisoquine (CYP2D6) and losartan (CYP2C9) in vivo. Eur J Clin Pharmacol 62, 539-546 (2006).

66. J. Kim et al., Identification of anti-malarial compounds as novel antagonists to chemokine receptor CXCR4 in pancreatic cancer cells. PLoS One 7, e31004 (2012).

67. L. Jia et al., In vitro and in vivo antitumor effects of chloroquine on oral squamous cell carcinoma. Mol Med Rep 16, 5779-5786 (2017).

68. M. Mauthe et al., Chloroquine inhibits autophagic flux by decreasing autophagosome-lysosome fusion. Autophagy 14, 1435-1455 (2018).

69. M. Norris, B. Fetler, J. Marchant, B. A. Johnson, NMRFx Processor: a cross-platform NMR data processing program. J Biomol NMR 65, 205-216 (2016).

70. B. A. Johnson, Using NMRView to visualize and analyze the NMR spectra of macromolecules. Methods Mol Biol 278, 313-352 (2004).

71. P. Michiels et al., Assignment of the orphan nuclear receptor Nurr1 by NMR. Biomol NMR Assign 4, 101-105 (2010).

72. M. P. Williamson, Using chemical shift perturbation to characterise ligand binding. Prog Nucl Magn Reson Spectrosc 73, 1-16 (2013).

\section{ACKNOWLEDGEMENTS}

This work was supported in part by National Institutes of Health (NIH) grants R01GM114420 (D.J.K.) and S10OD021550 (which along with institutional funds from Scripps Research funded purchase of the Bruker $600 \mathrm{MHz}$ NMR).

\section{AUTHOR CONTRIBUTIONS}

P.M.T. and D.J.K conceived and designed the research. P.M.T. performed cellular assays and protein NMR analyses. H.L, P.K, and T.M.K. synthetized compounds. I.M.S.dV. contributed to preliminary NMR studies on this project. D.J.K. analyzed data and supervised the research. P.M.T. and D.K. wrote the manuscript with input from all authors. The authors collectively declare no conflicts of interest in the completion of this study. 